Dicenda. Estudios de lengua y literatura españolas

ISSN-e: $1988-2556$

http://dx.doi.org/10.5209/DICE.62135

\title{
El concepto de tradición clásica y su permanencia en la poesía contemporánea española (de 1950 a la actualidad)
}

\author{
Eva Álvarez Ramos ${ }^{1}$
}

Recibido: 1 de abril de 2016 / Aceptado: 11 de noviembre de 2016

Resumen. El uso de motivos grecolatinos puede ser tomado como hilo conductor que nos guía -nuevo hilo de Ariadna- por el laberinto poético de las últimas décadas. Su importancia es tal que obliga a reflexionar sobre el concepto de clásico y su permanencia. Del mismo modo da pie a analizar cuáles son los modos acomodativos de la tradición grecolatina en las últimas décadas poéticas; cómo reinterpretan el sentido clásico y lo actualizan. Precisamente, tanto el mito como el acervo de los clásicos lo son por su capacidad de dar cauce a diferentes mensajes, amoldarse a diversas estéticas y no solo como adorno, sino como expresión propia.

Palabras clave: Tradición clásica; Culturalismo; Poesía contemporánea española; Revisión del mito.

\section{[en] The concept of the classical tradition and its permanence in Spanish contemporary poetry (from 1950 to the present)}

\begin{abstract}
The use of Greco-Roman motifs can be taken as a common thread to guide us -new Ariadne's thread-through the poetic labyrinth of recent decades. Its importance is such that it forces us to reflect on the concept of classic and continuity. Similarly, it gives cause to analyze which accommodative modes are of the Greco-Roman tradition in the recent poetic decades; how they reinterpret the classic sense and bring it up to date. Indeed, both the myth and the heritage of the classics, they are such for their ability to provide different messages, adapt to diverse aesthetics, and not only as an ornament but also as expression itself.
\end{abstract}

Keywords: Classical tradition; Culturalism; Spanish contemporary poetry; Myth review.

Sumario: 1 . El concepto de tradición clásica; 2. Tradición clásica, literatura e imitación; 3. La concepción de lo clásico y su permanencia; 4 . Tradición clásica y poesía española contemporánea; 4.1. La desmitificación regeneradora del mito; 4.2. Parodia, ironía y sarcasmo del mito; 4.3. El pasado mítico como futuro; 5. Conclusiones.

Cómo citar: Álvarez Ramos, E. (2018). El concepto de tradición clásica y su permanencia en la poesía contemporánea española (de 1950 a la actualidad), en Dicenda. Estudios de Lengua y Literatura Españolas, $36,9-31$.

Para escribir tiene que haber un vínculo estrecho con la tradición. Doris Lessing, "No ganar el premio Nobel"

\footnotetext{
1 Universidad de Valladolid

evamaria.alvarez.ramos@uva.es
} 


\section{El concepto de tradición clásica}

El término "tradición clásica" fue forjado por Gilbert Highet en 1949, año en el que se publicó La tradición clásica: influencias griegas y romanas en la literatura occidental; la expresión fue tomada de la obra Virgilio nel medio evo, de Doménico Comparetti, obra que recoge el vocablo y que Gilbert cita en varias ocasiones en su manual (Laguna Mariscal, 2004a). Las diferencias de significado son claras, puesto que Comparetti mantiene el concepto tal y como se concebía en la Edad Media: "el legado grecolatino pagano", mientras que Highet ya lo menciona como la influencia de la cultura clásica en el mundo moderno (Laguna Mariscal, 2004b).

Hasta el establecimiento de este término, la crítica trabajó con otras denominaciones, entre las que caben destacar las más empleadas ${ }^{3}$ : legado (Livingstone, 1921; Bailey 1923; Gómez Espelosín, 2003; Finley, 1984 y Jenkyns, 1992), herencia (Cuenca, 1978; VV.AA., 1979; Bolgar, 1954; Buck, 1980) y permanencia ${ }^{4}$ (Springer; 1867; Immisch, 191 y Newald, 1931).

Entre la multitud de definiciones encontradas queremos destacar tres por aportar, las mismas, los pilares fundamentales de este concepto. Vicente Cristóbal la considera: "la disciplina que se ocupa del estudio histórico-comparativo entre elementos culturales a los que debe unir el nexo de la dependencia, ya directa o indirecta, y de los cuales el emisor debe pertenecer a la cultura antigua de Grecia o Roma" (Cristóbal, 2005: 40). Para Luis Antonio de Villena, "sería la pervivencia histórica de temas, actitudes y modos de los escritores grecolatinos a través de las literaturas occidentales, desde la Edad Media hasta ahora mismo" (Villena, 2000: 68). Laguna Mariscal, en una definición que a nosotros nos parece más adecuada-aunque no del todo correcta-, afirma que:

la influencia directa e indirecta que ha ejercido la cultura clásica en el mundo occidental moderno, en todos los ámbitos de la cultura y de la civilización, incluyendo muy especialmente la lengua, la literatura, la arquitectura y el arte, el derecho, la ciencia, el deporte, la religión y el pensamiento (Laguna Mariscal, 2004a: 412).

Hemos preferido a Laguna Mariscal por hablar de influencia y no de disciplina, por utilizar conceptos como mundo occidental moderno y por especificar los ámbitos de actuación de la misma. Sin embargo, no podemos dejar de señalar que Laguna Mariscal cae en una tautología, al definir clásica utilizando el mismo concepto. Posiblemente, su definición hubiera ganado en perfección modificando "cultura clásica" por "cultura grecolatina".

2 "È tale infatti l'uso che abbiamo veduto farsi di quel nome nelle espressioni d'odio o di disprezzo, di amore o di stima per gli antichi scrittori pagani, che evidentemente ne risulta essere, per tutti gli scrittori del medio evo, Virgilio il sommo rappresentante dell'antica tradizione classica". D. Comparetti (1872), p. 128. "En efecto, es tal el uso que hemos visto hacerse de aquel nombre en las expresiones de odio o de desprecio, de amor o de estima por los antiguos escritores paganos, que evidentemente, Virgilio resulta ser, para todos los escritores de la Edad Media, el sumo representante de la antigua tradición clásica”. [La traducción es nuestra].

3 Laguna Mariscal hace un pequeño y excelente repaso a las vicisitudes sufridas por el concepto. Especial mención merece también el tratamiento histórico del empleo de "Tradición Clásica" (2004b: 88).

4 Término más difundido en el campo alemán con sus dos sinónimos: Nachleben y Fortwircken. 


\section{Tradición clásica, literatura e imitación}

Aunque durante la Edad Media se practicó, en rigor, una intensa y, a su modo, creativa imitación del legado grecolatino, es en los siglos XVI y XVII cuando esta imitatio se produce desde la profunda conciencia de salto, de ruptura y recuperación. Esto se produce en gran medida por la valoración negativa, en cierta manera prejuiciada, que el Humanismo tiene de los "siglos oscuros" medievales (con todo, puede verse ya una marcada conciencia de salto cultural en la afirmación que Juan de Salisbury atribuye a Bernardo de Chartres: quasi nanos, gigantium humeris insidentes ${ }^{5}$ ). Desde el Renacimiento la literatura latina fue concebida como modelo a seguir o imitar,

La literatura romana $[\ldots]$ más que cualquier otra literatura nacional influyó en las formas y modos de pensamiento de las letras europeas posteriores. Durante más de quince siglos después de Virgilio y Livio, el latín siguió siendo la lengua de cultura de Europa, evocando constantemente los grandes auctores del período clásico. Después, junto a los escritos en latín de la Alta Edad Media y el Renacimiento, las literaturas vernáculas de los siglos XIII al XVI asimismo se enorgullecen de descender a los antiguos romanos, que continúan inspirando a las literaturas de Occidente después del Renacimiento (Walsh, 1989: 849).

Debido a la Romanización, el tronco de familias latinas es mucho más amplio que la descendencia familiar de las lenguas helénicas y transmitir una lengua lleva adscrito, de forma directa la difusión de su cultura, es decir, su literatura. No debemos olvidar que la mayor parte del léxico de nuestra lengua procede del latín; aproximadamente las tres cuartas partes. El caso de la influencia helénica es harto distinto, puesto que, debido a la lejanía lingüística e histórica, accedimos a los griegos -en un primer momentoa través de los romanos; pero la huella helénica está, también, viva en nuestra cultura y contribuye al concepto de "tradición clásica". García Gual afirma que "griegos y romanos son significativa y fatalmente nuestros primeros clásicos, los clásicos por excelencia, comunes a todo el Occidente, puntales de la cultura europea" (2001: 256).

La utilización de autores clásicos en la literatura renacentista era un ejercicio poético altamente considerado, "no se valoraba especialmente la originalidad absoluta de la obra [...] se prestigiaba la imitación cabal de modelos clásicos" (Laguna Mariscal, 2001: 43) hasta el punto de que los comentaristas, retóricos, preceptistas y humanistas de la época defendían y ensalzaban esta praxis poética. Fernando Lázaro Carreter establece que "en la literatura del Renacimiento, la imitación literaria de modelos anteriores (especialmente grecolatinos) era un principio básico e incuestionado de práctica poética" (1979: 98). Por citar algunos casos, tomemos, por ejemplo, al Brocense y Juan Díaz Rengifo. Este último en su Arte poética española (1592) reconoce que cualquier arte poético es admirable, puesto que enseña el valor y las peripecias de nuestros antepasados, hecho que nos estimula y nos incita a su imitación (Paraíso, 2000). Sánchez de las Brozas es mucho más descriptivo en su valoración de la imitatio clásica:

digo, y afyrmo, que no tengo por buen poeta al que no imita los excelentes antiguos. Y si me preguntan, porqué entre tantos millares de Poetas, como nuestra

\footnotetext{
"Que somos como enanos a hombros de gigantes". [La traducción es nuestra].
} 
España tiene, tan pocos se pueden contar dignos deste nombre, digo, que no ay razon, sino porque les faltan las ciencias, lenguas, y dotrina para saber imitar. Ningún Poeta Latino ay, que en su genero no aya imitado a otros, como Terencio a Menandro, Seneca a Euripides; y Virgilio no se contentó, con caminar siempre por la huella de Homero; sino también se halla aver seguido a Hesiodo, Theocrito, Euripides, y entre los Latinos a Ennio, Pacuvio, Lucrecio, Catulo, y Sereno (1766: 36).

Eliot reconocerá, siglos más tarde, la importancia de la permanencia de la tradición y llegará a aseverar -siguiendo los preceptos de las poéticas clásicas- que es una de las características que debe poseer el poeta:

Ningún poeta, ningún artista, posee la totalidad de su propio significado. Su significado, su apreciación, es la apreciación de su relación con los poetas y artistas muertos. No se le puede valorar por sí sólo; se le debe ubicar, con fines de contraste y comparación, entre los muertos, y esto lo propongo como un principio de crítica no meramente histórica, sino estética (2004: 66).

La doctrina de la imitación renacentista se produce más como una necesidad que como una mera copia o plagio. Nadie puede ser considerado como un buen poeta si en su obra no existe la imitatio auctoris (Viñas Piquer, 2008) -lo que nos remite a la opinión anterior de Eliot-. Es la honra del hurto ${ }^{6}$, de la copia despiadada pero encumbrada. Podemos citar a Mendoza y Castillejo, como ejemplos de este robo consensuado y permitido (en este caso a Catulo), donde el libre albedrío del poeta se reduce a las dificultades cognitivas de la obra imitada o a la dificultad de adaptación del metro clásico (Álvarez Ramos, 2015). Los versos del carmen 72 de Catulo "Cogit amare magis, sed bene uelle minus" 7 (2006: 408-409) se transforman en Mendoza en "Quiérote menos bien y ámote más" (Castro, 1950: 136) o estos "Viene mezclado amor con aborrecimiento y no se puede creer si no se siente" son la transcripción de "Odit et amo. Quare id faciam, frotasse requiris? / nescio, sed fieri sentio et excrucior"' (2006: 436-437).

Caso semejante sucede con Castillejo, donde los anteriores versos de Catulo de "Odit et amo" se ven representados en estos dos poemas: "A la misma Ana" y "Otras coplas al amor":

Amo y quiero, aborrezco y desespero todo junto y por qué preguntado, no lo sé, más siento que es así, y muero (Castro, 1950: 408).

Aborrezco en demasía, pero menos que debería, vuestras obras de leona;

\footnotetext{
6 Morrós distingue dos tipos de robo: el ciceroniano, que se ciñe a la imitación de un único modelo, y el erasmista, que se ocupa de varios modelos y no se restringe en exclusiva a uno solo (Cfr. Morrós Mestres, 1998: 260).

“A sentir más amor, y a querer menos" [traducción de Juan Antonio González Iglesias (2006)].

8 "Odio y amo. Quizá me preguntes por qué. No lo sé pero así lo siento. Y sufro" [traducción de Juan Antonio González Iglesias (2006)].
} 
más amo vuestra persona

mil veces más que querría (Castro, 1950: 407).

Los dos poetas del XVI, aunque opuestos en pensamiento - uno seguidor de la corriente italianizante promulgada por Garcilaso y otro contrario a ella- van a coincidir sorprendentemente en la manera de adaptar los versos del italiano para introducirlos en sus obras. Estos dos autores leen con avidez e introducen rápidamente los versos eróticos de Catulo a su particular concepto renacentista de imitación de la poesía antigua, la cual no solo inspira los versos de Mendoza o Castillejo, sino que reproduce y se calca con evidente literalidad, aunque ciertamente variada por mor de los condicionantes métricos en su poesía (Arcaz Pozo, 2002: 15).

El modus imitativo se mantendrá hasta la centuria del diecinueve y la copia servirá como una auctoritas medieval que infunde un mayor valor a las obras y las catapulta a formar parte del canon de los autores consagrados. Este tipo de imitación, aquella que copia de manera gemela las fuentes, no ha desaparecido - mutatis mutandis - del todo en nuestra literatura. Podemos comprobarlo en estos versos de Carlos Barral, que discurren de manera paralela al carmen 4 de Catulo (2006: 194-195)':

Esta barca que veis, amigos míos, dice haber sido tan ligera nave que nunca fusta alguna al ímpetu del trapo ni de las palas la avanzó en su ruta (1991: 31).

Esto es debido al gusto por las labores de traducción del barcelonés que "por muchas razones personales, me ayuda en los trámites de la vida diaria, me exige diccionario. Paso los fines de semana en eso, traduciendo con ayuda de diccionarios porque no sé suficiente latín" (Riera, 1988: 17). La clara finalidad autobiográfica de estos versos queda patente en el paralelismo vital que Barral encuentra con el veronés. Los dos poemas se escriben a la vuelta de un viaje, Catulo en su regreso a Sirmio, Carlos en su vuelta a Calafell, locus de retiro de los últimos años del poeta (Saval, 2002).

El proceso creativo, tal y como comenta el propio Barral, parte de una traducción que adaptará después a su momento vital, transformando los puntos geográficos y asentando los versos en la costa mediterránea catalana ${ }^{10}$

Dice que no pueden negarlo las tormentas, la ventisca de Creus, las ráfagas del Cabo, el mistral amarillo de las altas murallas, los terrales del Golfo y los del Delta y el parapeto de los montes grises donde fue selva antes de ser navío ${ }^{11}$ (1991: 31-32).

9 "Este barquito que aquí veis, señores, / afirma ser la nave más veloz / y que nunca ha podido adelantarlo / cualquier otra madera que flotara, / volando ya con remos, ya con vela" [traducción de Juan Antonio González Iglesias (2006)]. La metáfora del barco como correlato del yo se convirtió en uno de los motivos más fecundos en el siglo de oro español, tal y como recoge Javier Blasco Pascual. J. Blasco Pascual (2016)

10 Puede comprobarse cómo se lleva a cabo este proceso, pues Barral en sus diarios nos presenta el plan de trabajo y las intenciones (Barral 1993: 256-259 y Saval 2002: 280).

11 En Catulo: "Niega que esto lo nieguen las orillas / del peligroso Adriático, las islas / Cícladas, Rodas la preclara, Tracia / arisca, su Propóntida, el salvaje / golfo de Ponto, cuando este navío / antes de serlo fue bosque frondoso" (2006: 194-195). 
Pero incluso aquí, lugar en el que la poesía contemporánea se acerca a la imitación antigua, la perspectiva poética no es la misma, ha cambiado el modelo clásico que ya no se concibe solo como aquello que invita a la copia o a la repetición, sino que se ve como sugerencia, como referencia de innegable validez, como una orientación reinterpretativa (García Gual, 2001). Muchos de los poetas contemporáneos que gustan del uso de la tradición clásica han sido grandes traductores de latín y griego, tal es el caso de Enrique Badosa, Luis Alberto de Cuenca, Aurora Luque y Juan Antonio González Iglesias entre otros. El papel que cumple el ejercicio de la traducción -como apunta Díaz de Castro- "proporciona motivos, temas, formas y figuras que determinan la creación propia más allá de las variaciones sobre tema clásico. [...] la tradición clásica cumple un papel fundamental y sostiene aspectos de su poesía" (Díaz de Castro, 2012: 64-65). Para Bourdieu, el campo de la traducción no es una mera copia del original, lleva adscritos otros elementos que permiten al poeta hacer público lo que ama y que refuerza su posición, aunque sea con usos instrumentalizados (Bourdieu, 1999: 163). Tal es el caso, por ejemplo, de esta otra "traducción" de Arturo Dávila. En su poema "X”, el barco es sustituido por un automóvil, los referentes geográficos se ven intercambiados por Montecarlo, Detroit o Río de Janeiro y las referencias marineras son suplantadas por asfalto, llantas...

Aquel auto que veis, amigos míos, dice que fue el más veloz de los coches

y que en su carrera podía pasar

a otros intrépidos bólidos

-de velocidades o automáticos-

y que cuando era necesario

casi volaba.

Y no lo niegan ni las pistas de Montecarlo

-en la Costa Azul del Mediterráneo-

ni las cálidas playas de Río de Janeiro,

ni el feroz calor de Detroit en el verano,

porque con sus llantas hería

el asfalto ardiente

silbando como una bala (2003: 19-20).

\section{La concepción de "clásico" y su permanencia}

Cabría preguntarnos sobre el porqué de esta permanencia y replantearnos todas y cada una de las acepciones que da el DRAE sobre "clásico", puesto que no solo esta tradición lleva la etiqueta por su origen grecolatino, sino evidentemente por su continuidad y -parafraseando- 'por modelo digno de imitación en cualquier arte o ciencia'.

Quizá el punto de partida lleve adherido el paso obligado por el término "clásica" y reflexionar brevemente sobre qué se concibe cómo "clásico", por qué un autor o un texto llevan adscrito dicho calificativo, qué les hace portadores de dicho halago o, ciertas veces, dicho handicap, puesto que pocas son las obras grecolatinas que han 
eludido la etiqueta de clásicas. Así, uno de los grandes mitómanos de lo clásico -en sus dos acepciones-, Borges, dice lo siguiente:

Clásico es aquel libro que una nación o grupo de naciones o el largo tiempo han decidido leer como si en sus páginas todo fuera deliberado, fatal, profundo como el cosmos y capaz de interpretaciones sin término. [...] Una preferencia, bien puede ser una superstición. Clásico no es un libro (lo repito) que necesariamente posee tales o cuales méritos; es un libro que las generaciones de los hombres, urgidas por diversas razones, leen con previo fervor y con una misteriosa lealtad (Borges, 1992: 367).

Los mismos elementos encontramos en la definición dada por García Gual, rasgo inequívoco y no negado de que parte de la opinión vertida por el argentino:

llamamos clásico a un texto avalado por un largo prestigio, de siglos y generaciones de lectores, un texto leído con fervor y que puede ser releído una y otra vez, que, a pesar de la distancia, nos sigue interesando y conmoviendo, porque siempre dice algo profundo y luminoso $(2001: 256)^{12}$.

La idea de la relectura aparece también en Calvino, para quien "un clásico es un libro que nunca termina de decir lo que tiene que decir" (Calvino, 2009: 15). Idea compartida por Azorín, para quien los clásicos no son tales, "si no refleja[n] nuestra sensibilidad. [...] Por eso los clásicos evolucionan, evolucionan según cambia y evoluciona la sensibilidad de las generaciones. [...] No han escrito las obras clásicas sus autores; las va escribiendo la posteridad" (1920: 15).

Las características que ha de presentar un libro para ser considerado como tal, no son susceptibles de ser explicadas y aclaradas, pero hacen, entre todo lo especificado con anterioridad, que dicho libro pase a formar parte de la conciencia colectiva de una nación o de una cultura.

En el momento actual no encontramos dificultad alguna para definir o entender intuitivamente "clásico", lo que sí encierra una mayor dificultad es establecer cuál es el canon de esas obras. La concepción del término es variable y maleable dependiendo de la perspectiva sobre la que se asiente el análisis; no se puede hablar, por tanto, de un canon cerrado, universal y absoluto: "Un determinado autor o texto puede entrar o salir del canon, según los cambios de gusto de las épocas, y la selección se presta a nuevas ampliaciones. [...] Cambian las preferencias según las épocas" (García Gual, 2001: 256-257). Y son precisamente, esas nuevas adquisiciones y esas pérdidas -lato sensu su forma y fondo-, las que han ido configurando a lo largo de la historia el concepto de tradición. Del mismo modo cambian y se modifican las lecturas, lo que permite insuflar aliento a estas obras y mantenerlas con vida, así como alimentarlas de los nuevos significados que con el tiempo y los receptores van surgiendo:

Deux démarches sont ici possibles. On peut aller vers le classique pour le retrouver dans son contexte en historien, en philologue, à travers une restitution érudite.

12 Paradigma sería, por ejemplo, la relectura actual de los "novelistas griegos y latinos" que acaban de ser redescubiertos, o el hecho, tal y como apunta, García Gual, de que ahora nos gusten menos Cicerón, Séneca o Plutarco que a los lectores de hace un siglo. 
Cette démarche Kermode la nomme herméneutique. L'autre démarche possible est une démarche accommodatrice. Par accommodation, nous rapprochons le chef-d'œuvre de nous, de notre temps, de nos intérêts de notre écoute. Immergé dans nos intérêts du moment, le chef-d'œuvre se transforme et se rénove. [...] Le texte classique permet donc une pluralité de lecture dans le temps. [...] en somme Kermode nomme texte classique ce que Barthes nomme texte moderne: un texte ouvert et virtuellement plurisignifiant (Schlanger, 1992: 87) ${ }^{13}$.

Esta concepción de "huella clásica" es inevitable en el concepto que estamos tratando. Todo clásico lleva adscrito el estigma de todas las lecturas anteriores a la nuestra y junto a ella "la huella que han dejado en la cultura o en las culturas que han atravesado” (Calvino, 2009: 15). Porque tal y como aclara Jaime Siles:

Nos inscribimos en una tradición y escribimos sólo desde ella, que es la que nos escribe a nosotros. Y nos inscribimos en una tradición $-\mathrm{y}$ no en otra- porque esa tradición -y no otra- se acomoda no sólo a nuestro modo de ser sino también a nuestro modo de leer: a lo que buscamos en la lectura y a lo que obtenemos de ella (1991: 17).

Somos hijos de Roma y nietos de Grecia ${ }^{14}$, es difícil borrar el pasado histórico de una cultura, la occidental, que ha sido reconstruida una y otra vez, sobre las ruinas grecolatinas. Javier Almuzara cree que:

Para que un poeta me emocione ha de saber a dónde va sin olvidar ni ignorar en ningún momento de dónde viene. Ha de conocer el valor justo de la originalidad, que es la interpretación personal de la tradición (de su propia tradición, por supuesto) (García Martín, 1995: 193).

No podemos negar el valor histórico de la tradición, pero en esta ecuación hemos de tener en cuenta, asimismo, otros elementos que han contribuido a la permanencia de la misma: la necesidad, el culto -casi fetichista- y la educación.

Aun así, no deja de sorprendernos su exacerbado uso, para dejarlo en mera anécdota descriptiva... ¿Nos lleva esto a pensar que todas las fuentes creativas se han extinguido?, ¿que los poetas actuales viven en un campo en barbecho?, ¿que el germen creativo ha sido asolado? Benjamín Prado lo resume de manera certera: "quien no conozca de forma exhaustiva la tradición no podrá ir muy lejos, pero tampoco quien no sea capaz de escaparse de ella" (García Martín, 1999: 68). ¿Acaso, y citando a Beckett, ya no hay nada más que decir? ..., pero es necesario seguir hablando. Pen-

13 "Dos caminos son posibles aquí. Podemos acercarnos al clásico en su contexto histórico como filólogos, restituyéndolo de forma erudita. Esta actitud es lo que Kermode considera como proceso hermenéutico. El otro camino posible es el acomodativo. Nos acercamos a la obra maestra aproximándola a nuestro tiempo, a nuestros intereses a nuestra escucha. Sumergida en estos nuevos intereses la obra clásica se transforma y renueva. El texto clásico, permite, entonces, una pluralidad de lectura en el tiempo. Resumiendo, Kermode llama Texto clásico a lo que Barthes llama Texto moderno: un texto abierto y virtualmente plurisignificante". [La traducción es nuestra].

14 Highet, sin embargo, prefiere reconocer otro parentesco: nietos de Roma y bisnietos de Grecia (1996), p. 11. Alfonso X por su parte, recupera la cita de Prisciano, de su Libro mayor, al decir, "los griegos son fuentes de los saberes e los latinos arroyos que manan d'aquellas fuentes de los griegos" (2009: 76a26). Sea como fuere los lazos consanguíneos son más que evidentes y las herencias genéticas incuestionables. 
samos en que quizá no haya nada que decir, pero esa necesidad de seguir hablando nos lleva directamente al germen de la cuestión: el cómo decirlo. Y aquí la tradición abre nuevos canales.

Queremos pensar que existe algo mucho más alejado de la repetición, que lleva consigo una nueva perspectiva que abre otros caminos de conocimiento; que, permeablemente, permite tanto al autor como al receptor empapar las vivencias; que, realmente, los clásicos son lo que su vocablo por ley semántica representa: aquellos que encierran mucho más allá de sus palabras y que son dignos de ser reconstruidos, edificados y transgredidos una y otra vez. El proceso siempre es dinámico, "la tradición no representa una herencia estática, sino una construcción siempre renovada por las lecturas que se llevan a cabo desde el presente [...]" (Gruia, 2009: 67). Es lo que Eliot describe, tal y como recoge Langbaum, como la "tradición diseñada por mentes modernas para un propósito moderno" (1996: 64). Ese moderno tradicionalismo que él reconoce en el Ulises de Joyce (93), puesto que nadie como el irlandés para ser un clásico en un ambiente moderno:

In using the myth, in manipulating a continuous parallel between contemporaneity and antiquity, Mr. Joyce is pursuing a method which others must pursue after him. [.... It is simply a way of controlling, of ordering, of giving a shape and a significance to the immense panorama of futility and anarchy which is contemporary history. It is a method already adumbrated by Mr. Yeats, and of the need for which I believe Mr. Yeats to have been the first contemporary to be conscious. It is a method for which the horoscope is auspicious. Psychology (such as it is, and whether our reaction to it be comic or serious), ethnology, and The Golden Bough have concurred to make possible what was impossible even a few years ago. Instead of narrative method, we may now use the mythical method ${ }^{15}$ (Eliot, 1975: 177-178).

La tradición de por sí ha de ser entendida desde una doble vertiente, aquella que entronca con la transmisión de la misma y la que se constituye en torno a su recepción. Dentro de este último ámbito es donde se circunscribe tanto lo reproductivo (comentarios, traducciones, imitaciones...) como lo productivo (influjos, ecos, recreaciones, etc.) (Cristóbal, 2013). Y es, de esta última de donde bebe la casi totalidad de obras literarias hispánicas de los últimos 70 años.

\section{Tradición clásica y poesía española contemporánea}

Entre todos los temas y asuntos recurrentes, aquellos pertenecientes al mundo grecolatino son los que encierran un mayor simbolismo (Bergua Cavero, 2003 y Casanova, 2001), por lo menos en lo que a mundo occidental se refiere. La maleabilidad

15 "Con el uso del mito, con la manipulación de un paralelismo continuo entre la contemporaneidad y la antigüedad, el señor Joyce está llevando a cabo un método que otros deben seguir tras él [...] Es simplemente una manera de controlar, de ordenar, de dar forma y un significado al inmenso panorama de futilidad y anarquía que es la historia contemporánea. Es un método ya esbozado por el señor Yeats, y por cuya necesidad creo que el sr. Yeats ha sido el primer contemporáneo en ser consciente. Es un método que goza de un Horóscopo auspicioso. La Psicología (tal y como es, y sea nuestra reacción a ella cómica o seria), la etnología y la "rama dorada" se han dado cita para hacer posible lo que era imposible incluso hace unos años. En lugar del método narrativo, podemos usar ahora el método mítico". [La traducción es nuestra]. 
adscrita a estos temas y motivos es, precisamente, el elemento gestor de esta abrumadora recurrencia ${ }^{16}$. La presencia del mito en la poesía contemporánea es palpable porque en lo mítico se gestan un nutrido y variado grupo de historias y pensamientos, que dan cabida fácilmente a citas, apropiaciones y homenajes. Son los motivos más recurrentes, no solo por ser parte de nuestra herencia cultural mediterránea, sino porque sus hechos, personajes y circunstancias forman parte de la idiosincrasia del ser humano:

Es cierto que el mundo cultural griego con sus mitos y leyendas ha despertado a través de los siglos la fascinación de artistas de todos los ámbitos. Desde el siglo XIX toda una pléyade de poetas (John Keats, Percy Shelley, Friedrich Schiller, Friedrich Hölderlin, Algernon Ch. Swinburne, los parnasianos, Jena Moréas, Paul Valéry, Ezra Pound, Unamuno, por nombrar sólo algunos) han escrito una lírica teñida de resonancias helénicas. En la zona mediterránea, poetas italianos como Giovanni Pascoli y Salvatore Quasimodo, catalanes como Jeroni Zanné y Guerau de Liost, valencianos como Juan Gil-Albert, se han sentido atraídos por éste o aquel aspecto del mundo helénico. Pero el centro de interés de estas evocaciones en los poetas recientes no es aquel mundo lejano sino la vida de hoy (Cano Ballesta, 2007: 84).

Esta pluralidad semántica y adaptabilidad de las fuentes es precisamente la que permite a los poetas la individualidad, la que contribuye a diferenciarlos entre sí y a alejarlos del concepto cansino de repetición; aquello que se ha dado en llamar "dialéctica de la distinción": "las diversas maneras de relacionarse con las obras del pasado (i. e., negación, rechazo, parodia, restauración o rescate, etc.) constituyen un elemento esencial de diferenciación entre las obras" (Bergua Clavero, 2003: 19).

Uno de los puntales que asienta y establece a un libro como clásico es el concepto de relectura, que permite una doble perspectiva: por un lado contribuye a su permanencia a lo largo del tiempo, en la que generación tras generación leen con interés y se conmueven con lo dicho, pero, intrínsecamente unido a esta relectura y derivado de ella, está la interpretación, las múltiples lecturas (en este caso no en cuanto a cantidad, sino en cuanto a significados) que un libro clásico adquiere con el paso de los años. Es precisamente esta cualidad lo que concede al culturalismo una permisividad sin contemplaciones, ante la transformación y revisión del clásico, vivificándolo con cada nueva representación. Los clásicos llevan siempre impresa esa huella que los lectores a lo largo del tiempo les han ido imprimiendo.

Los motivos pertenecientes a la tradición grecolatina encierran un gran potencial que los poetas contemporáneos españoles (al igual que otros muchos literatos a lo largo de la historia) han sabido ver y optimizar. En el mito se encierra una gran variedad de hechos, personajes y pensamientos extensibles a cualquier circunstancia del ser humano. El mito es más que una historia ficticia, un relato etiológico al que recurren, fieles, las generaciones en busca de respuestas. En el mito se dan cita las vicisitudes del ser humano, el mito refleja su idiosincrasia. Citando a Alberto Manguel, "cada época vuelve a imaginar a los clásicos en su propio idioma" (2010: 206), porque los clásicos

16 El amplio repertorio que ha conseguido recuperar José María Camacho Rojo (1991, 2008, 2011 y 2012) en varias publicaciones, no viene más que a reforzar esta tajante afirmación y es testigo de la presencia de la tradición clásica en la literatura hispánica no solo en el período aquí tratado, sino a lo largo de su historia. Obligada mención merece el minucioso trabajo realizado por Rosa M. a Lida de Malkiel “prodigio de finura y erudición” (Cristóbal, 2013: 21). Pueden consultarse sus sistemáticas y excelsas investigaciones en Malkiel, 1962, 1966, 1974 y 1975. 
saben del alma humana, de sus debilidades, de sus grandezas y de sus miserias. No puede percibirse su presencia en la actualidad como una repetición fosilizada, sino que su carácter proteico en manos de los poetas, deriva en visiones de plena vigencia, que no dejan de mostrar esa actualidad de la Antigüedad. Los mitos universales se retoman siguiendo los preceptos señalados por las tendencias poéticas dominantes y los gustos personales de los poetas: "estos tópicos van a aparecer renovados, depurados o engendrados en nuevas temáticas o nuevas visiones y serán retomados conforme a las convenciones estéticas culturales predominantes" (Sánchez Dueñas, 2000: 555).

\subsection{La desmitificación regeneradora del mito}

Los hombres a lo largo de las épocas han intentado entender quiénes son; los mitos grecolatinos cuentan la vida y plantean preguntas; intentan, asimismo, dar alguna respuesta, pero existen interrogantes permanentes que fluyen a lo largo del tiempo, "la Antigüedad no es remota, se vuelve actual" (Olmo Iturriarte y Díaz de Castro, 2011: 9). Mitos grecolatinos y hombres modernos comparte los universales más profundos de la raza humana. Así, podríamos decir que el retorno de Ulises a casa acontece cada día en cualquier calle de cualquier ciudad, como lo muestra Salvago, en su extenso "Ulises" (1996: 39-43) ${ }^{17}$. La salida del hogar para ir a la Guerra de Troya, se muda aquí en la ida diaria a su trabajo como redactor publicitario: "[...] La vida, este inútil trabajo, esta batalla / a muerte y sin descanso, que le obliga a lanzarse / un día más, sin ganas ni ilusión, a la calle". La transposición entre el locus mítico y el real, puede resultar un tanto hiperbólico, pero no hace más que poner en evidencia que todo asunto cotidiano puede tener su halo mítico, o que por contraste se puede desmitificar incluso al héroe más mítico. Narra desalentadamente esta épica diaria del que ha sido absorbido por la rutina, del que existencialmente se interroga por su vida, en la que ha de combatir y superar los obstáculos que le van acechando: portera, esperas cansinas al transporte público, el caos circulatorio..., óbices correlatos de los clásicos Poseidón, Lestrigones, Lotófagos...

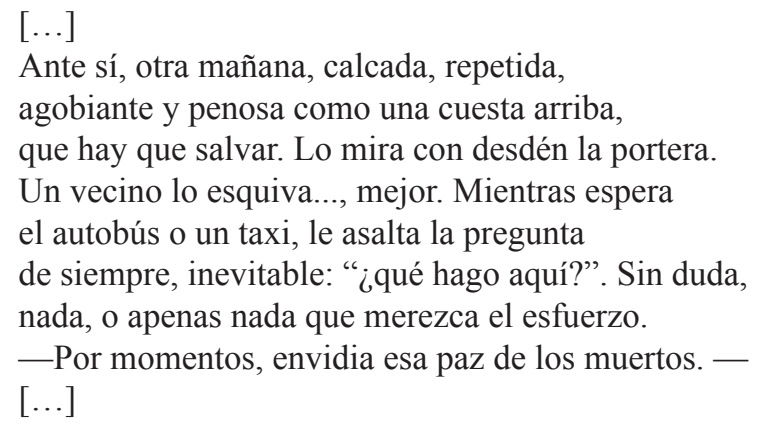

El cierre del poema con anticlímax nos devuelve al círculo iniciado al despertar del personaje. Este Ulises más próximo a su homónimo joyceano que al Odiseo

17 Para un estudio más detallado de este poema pueden consultarse, "Mito clásico y poesía española actual: el tema de Ulises en un poema de Javier Salvago" de J. L. Arcaz Pozo (1999) y “Javier Salvago: Ulises Urbano" de E. Barón (1999). 
homérico termina su día devastado por la verdad con "ese cupón para un suicidio postergado" (Baron, 1999: 135).

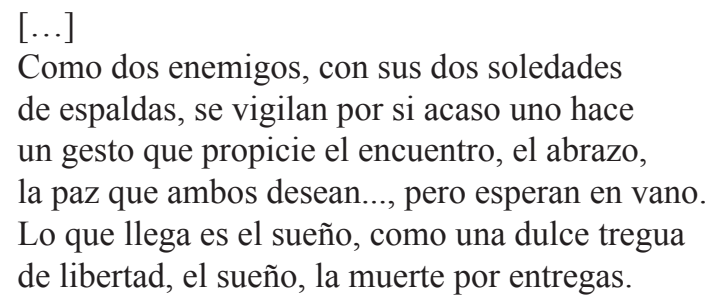

Fusiona, en esta "muerte por entregas" dos tópicos: el sueño hermano de la muerte (en Homero) y el quotidie moritur senequiano. En su composición, donde aparecen puntualmente lo que hasta aquí hemos señalado. Salvago poetiza el periplo de, "un Ulises que es el hombre de hoy, ese animal de ciudad que sale a diario a enfrentarse a su lucha particular y rutinaria y vuelve derrotado, que no tiene a Penélope tan paciente como la homérica ni un Telémaco tan preocupado por su padre que emprende su búsqueda" (Arcaz Pozo, 1999: 193).

La desgana, el desencanto y la decepción también se entremezclan en el novísimo y poco casto "Jasón" (2004: 225) de Julio Aumente. El héroe del poema ha finalizado ya su expedición a Frixo. Ya descansa su veloz nave: "No cruza el mar aquel dorado Argos / ni sus jarcias de seda ni su velamen púrpura: / hinchado pecho empuja el turbulento oleaje / abriendo con su quilla el hondo abismo".

El lugar de Jasón ahora es otro. Después de haber solventado muchos inconvenientes en su búsqueda del vellocino de oro, tras haber pasado tantas vicisitudes, se encuentra hoy decaído y desolado:

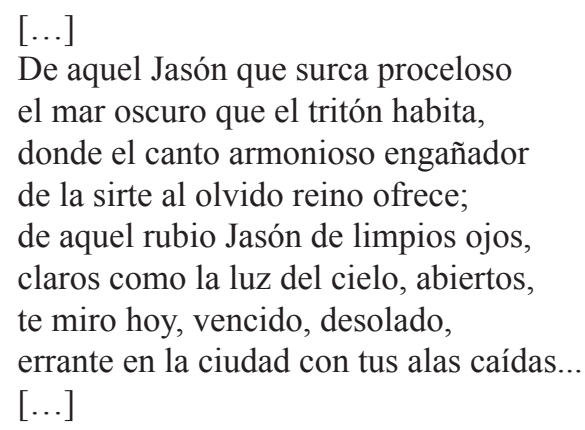

Después de la aventura y la gloria, perdido el vellocino y la sonrisa conserva todavía la belleza que utiliza para su propio beneficio: "Dónde tu vellocino, tu sonrisa invencible, / nauta ya naufragado, pecio inerte. / Hermoso aún, haciendo la carrera, / Jasón, desde la esquina de Prim a la calle Almirante...".

La des-mitificación que es, en realidad, una re-mitificación, pues, como ya se ha dicho, lo que distingue al "mito" de otras formas como la leyenda sería su capacidad para renovar su sentido etimológico. El relato del argonauta griego que vence, por la fuerza de la razón y la lógica modernas, al mundo bárbaro y primitivo de oriente (Medea), es ahora el relato de la juventud y la belleza gastadas en explorar "el turbulento oleaje", el "mar oscuro" de la marginalidad 
y la prostitución. La re-significación del mito se potencia por el contraste entre el lenguaje retórico, ornado, del poema (proceloso, sirte..., hipérbaton) y dos expresiones "canallas" que el poeta se guarda hábilmente hasta los dos versos finales: "haciendo la carrera" y "desde la esquina de Prim a la calle Almirante", donde la carrera no es, evidentemente, el cursus heroico, sino la prostitución, y "Almirante", que cierra de manera muy emblemática el poema, no es el título marinero que correspondería al capitán de la nave "Argos", sino una de las vías madrileñas tradicionalmente frecuentadas por "chaperos": este nuevo Jasón persigue un vellocino de un metal más vil que el oro, y despojado de las alas ("caídas") del Crisómalo...

No se desvirtúan en "Ulises" o "Jasón" la esencia mítica, puesto que la plurivalencia, el simbolismo subyacente y el polifacetismo característicos de estas historias permiten su adaptación e interpretaciones por culturas dispares en momentos diversos. Nos ofrecen una visión distinta de la leyenda clásica; no se hace, en ninguno de los dos, una copia a ultranza del sentido metafórico del viaje, pero esa (y no la repetición fosilizada) es precisamente la vitalidad del mito como tal mito ('relato etiológico') y no como ornato: "Los mitos clásicos perviven más allá de los imperativos poéticos y de las modas de turno, camuflados o revestidos con nuevos ropajes y encaminados a nuevos fines, pero al fin y al cabo renovados en estos ecos actuales y dotados siempre de plena vigencia" (Arcaz Pozo, 1999: 183).

La misma regeneración mítica se da, por ejemplo, en la obra de Aurora Luque. En "Los cantos de Eurídice" (1982: 29-35) será Eurídice la que elija el descenso a los infiernos y rechace la amorosa salvación, "una Eurídice hosca quiere bajar voluntariamente al abismo. No desea que el amor la salve ni rescate; su descenso es una opción vital, individual, irrenunciable" (Luque, 2006: 23). La encontramos también en "Camaradas de Ícaro I", donde Aurora, a través del monólogo dramático, asume la identidad del griego y extrapola la construcción de las alas a la creación de un poema:

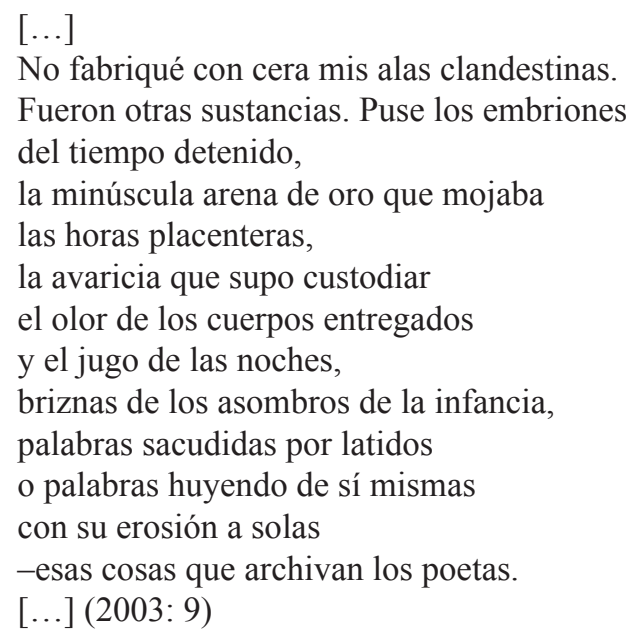

Para la almeriense, "todos los poetas somos en cierto modo camaradas de Ícaro: fabricamos nuestras propias alas con [...] las palabras "sacudidas por los latidos" o 
las palabras erosionadas [...]”' (2008: 34). Tal y como indica Carmen Morán Rodríguez, estamos aquí ante otra interpretación del mito que "ha visto en Ícaro al poeta, deseoso de alcanzar un ideal elevado al menos, en la concepción romántica, de raíz platónica, como lo es la de Luque" (2015: 451).

\subsection{Parodia, ironía y sarcasmo del mito}

La presencia de la parodia no resta ni un ápice de validez al sentido explicativo del mito, y con frecuencia los mismos poetas que caricaturizan la materia clásica también cultivan, muy quevedescamente, una faceta seria. Es el caso de Víctor Botas, uno de esos poetas en los que se despliegan distintas tonalidades, pasa de la gravedad a la neutralidad y de esta a la ironía. Nos encontramos con lo que él mismo denomina "la coña literaria" (1999: II): "la agudización burlona de la mirada con la que observa la realidad de un mundo que genera desasosiego y que la poesía solo puede tratar de afrontas desde la postura escéptica que sustenta la modalidad irónica" (Vara Ferrero, 2011: 208).

En “Teseo" (2012: 268-269), por ejemplo, estamos ante uno de los relatos más formulados por la tradición literaria, la historia del héroe y el laberinto. Botas accede al mito desde una perspectiva irónica contraria al romanticismo: Ariadna sería la única responsable de su abandono:

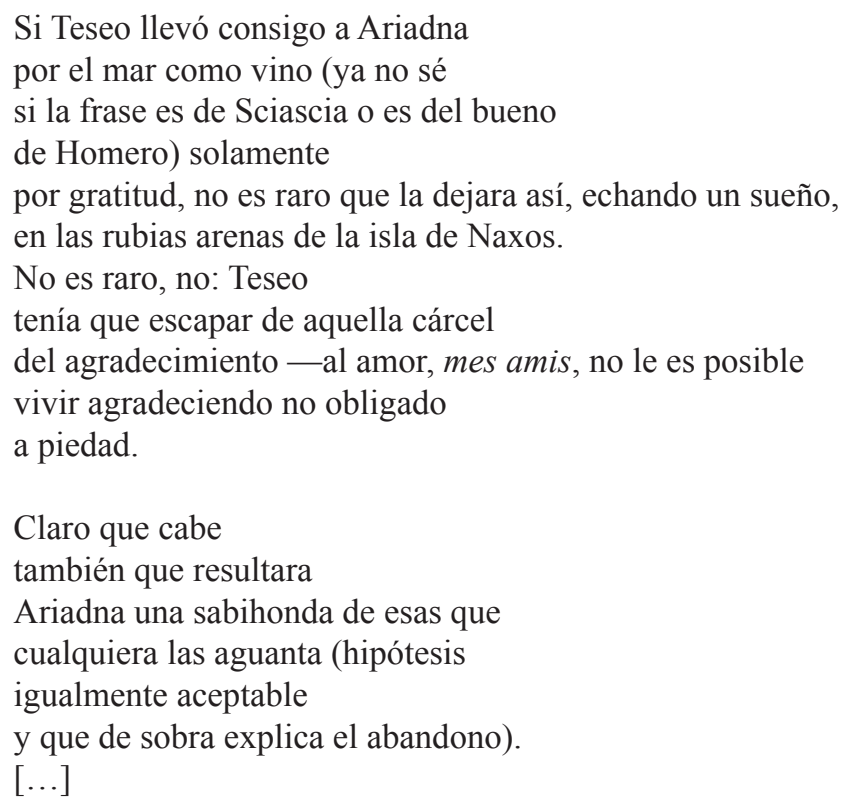

La nueva concepción de la historia mítica hace al lector cambiar la perspectiva de su visión de Ariadna; Botas no pasa por alto las posibilidades que pueden tener la actualización y mudanza del mito:

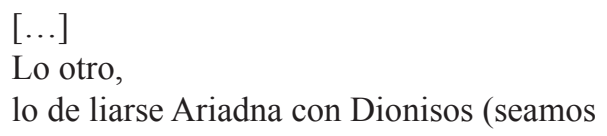




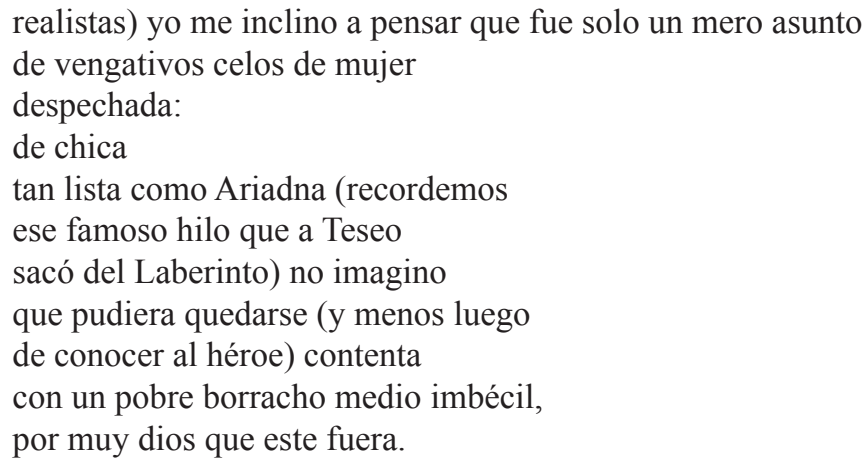

La tan usada ironía de Botas, le lleva a la degradación total del mito. Comenzando porque se refiere a toda una parte del relato mítico como "lo otro, / lo de...", fórmula que consigue reducir el mito a relato trivial. Después, se apoya en alguna historia personal en la que el poeta se identifica con Teseo, deja a su partenaire representar el papel de Ariadna, pero de una hija de Minos, muy particular a la que carga con todos los defectos y a la que le achaca todas las culpas de su ruptura. Justifica el poeta su pérdida o abandono (hay mucho de justificación en este insulto satírico), a través de una directa descalificación personal ("Ariadna una sabihonda de esas que / cualquiera las aguanta"), no solo de ella, sino de la persona que ahora es su pareja "un pobre borracho medio imbécil". Víctor Botas "toma prestadas las líneas esenciales del mito y las interpreta entre ironía y desapego" (Guerrero Contreras, 2001: 231). La maleabilidad de lo clásico permite la transgresión más directa y su supervivencia viene marcada

porque sus formas originales, variables y ágiles, posibilitan un vastísimo horizonte dentro del cual cabrá escoger retrospectivamente zonas muy diversas de inspiración, de acuerdo con la sensibilidad de la época o el temperamento y el proceso de selección del artista, a lo que habría que añadir la fácil contaminación o infección de componentes primitivos del mito renovados e incluso totalmente transformados a través de la tradición, viniendo a presentar en la actualidad nuevas significaciones al ser manipulados por la inversión de sus valores originarios (Sánchez Dueñas, 2000: 556).

Inversión que, de forma epigramática, como en el siguiente ejemplo, llega incluso a rozar el sarcasmo. Como ya mencionamos en otra ocasión (Álvarez, 2016), en "Cosas de mujeres" toma Inmaculada Mengíbar, la tradición epigramática de Marcial con sus agudos aguijonazos; y, de sus predecesores de los 50, aprovecha la vena irónico-humorística (Bagué Quílez, 2004: 14-15). La particular estructura del epigrama, su condensación expresiva y la intensísima concentración semántica final permiten, de forma rápida y certeza, destronar mitos, romper tradiciones y dar la vuelta a extendidas máximas. La transgresión de la cordobesa le lleva a enfrentarse a asuntos más delicados afrontados desde la perspectiva inversa, así se posiciona en la figura de la amante, no en la de la manida fiel esposa, "Pero seamos realistas: / Penélope, cosiéndole, / no es más feliz que yo / ahora mismo rompiéndole / la cremallera" (Mengíbar, 1994: 29). Hay una clara lucha contra este sistema patriarcal y la expansión arraigada del mundo 
masculino, para enfrentarse y poner en entredicho esta hegemonía androcéntrica echa mano del epigrama y de la crítica más irónica. Desbarata una figura mítica con la transposición del elemento que las relaciona, el hombre, para la que una cose y la otra descose, puesto que se convierte en el elemento subversivo. Se establece un margen diferencial; frente a la lentitud con la que Penélope cosía y descosía el tapiz en su larga espera, la amante se apresura, por el desaforado deseo derivado de la excitación sexual, hasta el extremo de no tener la paciencia de bajar una simple cremallera, sino que necesita, imperiosa, romperla. Una vez más, la poeta consigue escabullirse de los estereotipos creados en torno al universo femenino y con la mayor simplicidad lingüística muestra, sin oscurantismos, esta diferencia. Un ejemplo de cómo se transgreden y se amalgaman los mitos con la realidad más cotidiana.

Hay una doble lectura del poema: en la primera la voz poética ocupa la posición de la mujer-amante frente a la mujer-esposa, reflejada en la tradición, por el convencionalismo de la fidelidad más absoluta, en la figura de Penélope. Engloba en esta visión a todas las mujeres del periplo odiseico que no son Penélope: Circe, Calipso, Nausicaa..., para darles ese protagonismo que se merecen. El mismo que por extensión corresponde a cualquier amante vulgar y convencional ajena a las literarias. Pero, por otra parte, reivindica el poder femenino de la mujer, que disfruta de su sexualidad por encima de convencionalismos sociales, no importa el rango sentimental, ni la ausente firma en un papel, ni el simbólico y comúnmente deseado anillo; no importa que la relación sea de tres, en ese momento; lo que realmente importa es su disfrute sensitivo y placentero, más allá de tabúes y corsés ideológicos. Esta dualidad, además, queda plasmada en el título del poema, con "Cosas de mujeres", nos enfrentamos a un asunto de damas, como una actividad que tienen entre manos (comparten al mismo hombre, quizá podría hablar de una analogía entre cosa-objeto y el concepto transgresor de cosificar al hombre); y "cosas de mujeres" como unidad fraseológica referida a asunto o dicho que solo se comenta entre señoras, con lo que se está vetando el terreno a los hombres, de nuevo esta anulación andrógena. Sin olvidar, la connotación machista del concepto tradicional "cosas de mujeres", a la que da la vuelta. Es fundamental, asimismo, que el poema se inicie como intervención adversativa, puesto que conlleva la negación de lo comúnmente extendido: la glorificación de la fidelidad más sumisa frente a la degradación de la libertad sexual femenina.

\subsection{El pasado mítico como futuro}

No solo la gran carga simbólica de la que son portadores los clásicos es la que los hace necesarios; podemos, incluso, hablar de un efecto placebo en su uso que como anamnesis trae al presente los recuerdos del pasado: "A nadie que no sea ciego se le escapa que frente a un futuro puesto en duda y un presente inestable, transitorio, la única alternativa que queda es una mirada revitalizadora al pasado" (Milán, 2004: 85). Morano, por ejemplo, considera que la situación actual europea es muy semejante a la Grecia de los siglos V al IV, de ahí que frente al desengaño diacrónico compartido se tome como punto de referencia su cultura; "Frente al progreso técnico el hombre sigue en pie, eternamente hambriento de una felicidad que nunca llega" (Moreno, 1982: 87). No estamos pues ante un recurso meramente estético, sino que en la poesía española contemporánea la 
presencia de elementos griegos y latinos sirve para hacer más liviana la realidad circundante:

la cita, la comparación, la recreación de elementos de la Historia, de la Literatura o de la Mitología antiguas sirven sobre todo para hacer más llevaderas las inevitables verdades: la muerte, el paso del tiempo, el fracaso amoroso, la corrupción política, la ausencia de Dios (Arenas Cruz, 2003: s. p.).

Otros críticos prefieren denominarlo fetichismo (Bergua Clavero, 2003: 15), tomado, no como desviación sexual, sino como apunta el DRAE en otra de sus entradas 'el culto al que se atribuye poderes sobrenaturales, especialmente entre los pueblos primitivos'. Esos poderes a los que Bourdieu llama "capital simbólico", una propiedad con fuerza mágica que "ejerce una especie de acción a distancia, sin contacto físico" (1997: 173).

Porque lejos quedaron los clásicos y esa vuelta no hace más que recaer en la cíclica pregunta sobre el porqué de su necesidad, pero aquí ya no hay hipótesis porque los hechos están consumados:

El poeta tiene el gesto inocente de la vuelta, de voltear la cabeza para tratar de vislumbrar aquella lucecita que ilumine y devuelva el esplendor. Y eso es una necesidad real, no una mera fachada que encubre -al menos no todas las veces- la imposibilidad también real de encontrar nuevos medios expresivos que puedan dar cuenta de esa realidad que tanto ama (Milán, 2004: 80).

Ya no nos enfrentamos al éxodo que representó el Barroco o el Romanticismo, por poner algún ejemplo, el no querer ver lo circundante y evadirse a otros mundos lejanos, físicos y temporales, sino que ahora quizá la huida es atracción, de atraer de forma consciente todo aquello que ya pasó y se fue y asentarlo en el aquí y el ahora del poeta; son malos tiempos para la imaginación y evidentemente para los sueños. Los poetas, lúcidamente, conocen sus frustraciones y saben que la fuga completa no resuelve nada.

Y eso es lo que en nuestros días ha pasado: hartos de continuas y falsas rupturas, de seísmos aún más falsos que tenían que derrumbar todo lo inmediato (cuando la historia nos enseña todo lo contrario), se ha vuelto la mirada hacia la tradición (...) Si estamos fuera de la tradición -la que sea- estamos fuera de la cultura. Y lo que pretendemos -lo que siempre hemos pretendido- es ganar ese título, ser dignos de la civilización, y la libertad que implica (Villena, 2000: 59-60).

Esta huida, aunque retrospectiva, siempre es hacia adelante, "la presencia del mundo clásico, antes que volver la cabeza atrás, nos empuja a mirar hacia adelante $[. .$.$] pero mirar hacia adelante no significa en absoluto confiar en idea alguna$ de progreso" (Andújar Almansa, 2008: 12). Podemos verlo ejemplificado en este poema de Juan Peña "Malos tiempos para la épica" (1997: 9) (título que remeda el "Malos tiempos para la lírica" de Bertol Brecht que en los ochenta popularizó, como título de una canción, Germán Copinni en el grupo Golpes Bajos). La letra de la canción, por cierto, transmite a la perfección el espíritu de agotamiento pos- 
moderno que, sin embargo, tan rentable ha sido para la poesía, y concretamente para la tradición clásica.

Dónde aquellos fervores,
los altos ideales
y las nobles virtudes,
el genio, la energía,
la fuerza del espíritu
que empuñaba la espada.
El coraje y la audacia
han cedido su puesto
a los pactos cobardes,
a los blandos festines
y a las deslealtades,
a holgazanes y débiles
viviendo de sus lágrimas.

Se intuye la desconfianza en los versos, se palpa esa mirada al pasado comparándolo con un presente que se presenta poco alentador y que deja poco espacio para la esperanza. Pero este paliativo no se configura como el uso de vanas nostalgias eruditas,

el pasado no es un perdido paraíso al cual, sin excesiva convicción, se sueña con volver: nos interesa porque es presente; la entera tradición literaria europea nos aparece como una sucesión y como un "orden simultáneo" (como una "norma de momentos intemporales”, [...] (Gil de Biedma, 1999: 10).

Otros hay que reivindican esa vuelta a los clásicos como una lucha por mantener la tradición de la que quieren separarnos, Morcillo lo denomina el síntoma del "clásico contemporáneo" en los poetas de los setenta, "tales obras no pretenden ser manifiestos, pero aspiran a conducirnos, por medio de la relectura de las obras maestras clásicas, hasta la comprensión de la literatura en forma de una memoria cultural de la se nos quisiera desposeer" (2009: 15).

No cabe duda de que la tradición clásica forma parte inherente de la poesía contemporánea española y de que su reutilización se produce con fines muy diversos (Díaz de Castro, 2010) citas, imitaciones, relectura de mitos..., "se trata de un sincretismo multiforme que integra con muy distintas funciones y sentidos cualquier manifestación cultural, muchas veces trivializándola, casi siempre trasgrediendo, voluntaria o involuntariamente, su sentido original [...]" (65).

\section{Conclusiones}

La tradición clásica se presenta como una continuidad y evolución de géneros, tópicos y temas, aspectos de gran interés en la poesía española desde el último medio siglo anterior hasta los albores del presente y viene marcada más por una necesidad que por una mera copia o imitación al más estilo renacentista. Hay todavía mucho 
que decir de aquello que ya se dijo. Existen aún muchas variables de significado en los textos clásicos, la tradición no deja de ser el pilar maestro en el que se asienta nuestra cultura y nuestro pensamiento y, por ende, nuestra literatura. No tendría entonces sentido alguno la permanencia de la tradición clásica en la lírica contemporánea, aunque dicha estabilidad temporal traiga consigo variantes, máscaras y recreaciones.

En la poesía contemporánea de referentes clásicos se amalgama lo mítico con lo popular. Esa esencia popular en la que se entremezcla lo tradicionalmente común con la cultura más pop. Las dos aristas culturales difuminan sus límites y se combinan y entremezclan; la cultura popular y cotidiana convive con recursos de la conocida como alta cultura. La tradición grecolatina más rancia se moderniza, actualizándose y vivificándose a golpe de verso.

En todo caso la cuestión de fondo es que muchos poetas han visto en la tradición una ciudad en ruinas que puede ser reconstruida y reactualizada, incluso transformada y por qué no, habitada. Es el caso de las autoras, por ejemplo, que recurren a la subversión y a la revisión del mito para reivindicarse y expresarse; el uso de personajes míticos les permite, asimismo, construir diferentes manifestaciones de sí mismas.

Las obras de la tradición clásica dignifican y enriquecen el espíritu humano, hacen que descubra pasiones eternas, pensamientos perpetuos... La multiplicidad significativa que se adscribe a todo clásico, lo hace un ser dúctil y maleable, digno de adaptarse a cualquier momento histórico-social. Las generaciones, aun con sus diferencias, siguen manteniendo, ese inconsciente colectivo que las acercan con el paso de los siglos y les permite compartir y mantener, en ese sustrato común, los sentimientos, esperanzas y miedos, que ven reflejados en el clásico. Reflejan nuestra sensibilidad, evolucionan con nosotros y nos muestran quiénes somos, generación tras generación. La tradición se escribe día a día, lo clásico lo va trazando el porvenir.

Por último, la mixtura de lo cómico y lo serio, relacionada principalmente con el sincretismo de lo popular y lo tradicional, los nuevos pensamientos enmarcados en clásicos géneros, el uso de temas elevados bajo las premisas de lo cotidiano y lo irrisorio, a veces paródico... hacen del uso de lo culto un artificio perfecto en esta poesía contemporánea. Se vuelve a lo clásico, pero acercándolo al presente, prevalece un cierto carácter recreador. Se consigue renovar y dar frescura al mito sin dejar de lado la tradición, aunque se conciba muchas veces como juego. Se abre paso un tratamiento de la cita, el tema mítico, la alusión grecolatina ... más cercano, más coetáneo, más vivido. Lo culto se asimila para formar parte de la experiencia propia y ajena. El poder de la tradición permanece inamovible.

\section{Obras citadas}

Álvarez Ramos, Eva, "Presencia de la lírica amatoria de Catulo en los poetas españoles: del passer Lesbia a los basia mille", en Actas del XLIX Congreso Internacional de la AEPE. La enseñanza del español en el contexto de las artes y la cultura, Valladolid, AEPE, 2015, pp. 103-115.

—, "Penélope ya no quiere ser princesa: arquetipos femeninos de la tradición clásica en la poesía española contemporánea", en Tonos Digital. Revista electrónica de estudios filológicos, 31 (2016), pp. 1-14. 
Andújar Almansa, José, "Prólogo. Detrás de las palabras", en Una extraña industria, Valladolid, Servicio de Publicaciones de la Universidad de Valladolid, 2008, pp. 9-15.

Arcaz Pozo, Juan Luis, "Mito clásico y poesía española actual: el tema de Ulises en un poema de Javier Salvago", Exemplaria, 3 (1999), pp. 177-184.

—, "Pervivencia de Catulo en la poesía castellana", Alazet, Revista de Filología, 14 (2002), pp. 13-39.

Arenas Cruz, Elena, "Culturalismo y poesía: la mirada de Víctor Botas", Artifara, 3 (2003), s.p.

Aumente, Julio, Poesía Completa (1955-1999), ed. de Rafael Inglada, prólogo de Luis Antonio de Villena, Madrid, Visor, 2004.

Azorín, José, "Prefacio", en Lecturas Españolas, Madrid, Caro Raggio, 1920, pp. 13-16.

Bailey, Cyril, (ed.), The legacy of Rome, Oxford, Oxford University Press, 1923.

Barral, Carlos, Poesía, Madrid, Cátedra, 1991.

—, Los diarios, 1957-1989, ed. de Carme Riera, Madrid, Anaya y Mario Muchnik, 1993.

Barón, Emilio, "Javier Salvago: Ulises Urbano", en Literatura comparada. Relaciones literarias hispano inglesas (siglo XX), Almería, Universidad de Almería, 1999, pp. 131-138.

Bergua Cavero, Jorge, "La tradición clásica y el concepto de influencia", en Literatura Hispanoamericana del siglo XX. Mímesis e iconografía, Málaga, Servicio de publicaciones de la Universidad de Málaga, 2003, pp.11-21.

Bloom, Harold, [1994], El canon occidental: la escuela y los libros de todas las épocas, Barcelona, Anagrama, 2001.

Blasco Pascual, Javier, "Horacio, Ovidio, Catulo... y la salamanca de Fray Luis de León", Notas Hispánicas 1 (2016), pp. 1-3.

Bolgar, Robert R., The Classical heritage and its beneficiaries, Cambridge, Cambridge University Press, 1954.

Borges, Jorge Luis, "Sobre los clásicos", en Otras Inquisiciones, Obras completas, Vol. 2, Barcelona, Círculo de lectores, 1992, pp. 366-367.

Botas, Víctor, Poesía completa, Gijón, Llibros del pexe, 1999.

—, Poesía completa, Sevilla, La isla de Siltolá, 2012.

Bourdieu, Pierre, Razones prácticas. Sobre la teoría de la acción, Barcelona, Anagrama, 1997.

_- "Las condiciones sociales de la circulación de las ideas", en Intelectuales, política y poder, Buenos Aires, Eudeba, 1999, pp. 159-170.

Buck, August, L'eredità clássica nelle letterature neolatine del Rinascimiento, Brescia, Paideia Editrice, 1980.

Calvino, Italo, "Por qué leer los clásicos”, en Por qué leer los clásicos, Madrid, Siruela, 2009, pp. 13-20.

Camac, José M. ${ }^{\text {a }}$ "Bibliografía analítica sobre la tradición clásica en las literaturas hispánicas e hispanoamericanas del siglo XX: 2001-2005”, Florentia Iliberritana, 19 (2008), pp. 337-376.

Camacho Rojo, José M. a, "La tradición clásica en las literaturas hispánicas: esbozo de un ensayo bibliográfico", Florentia Iliberritana, 2 (1991), pp. 33-92.

—, "La tradición clásica en las literaturas hispánicas e hispanoamericanas del siglo XX. Bibliografía analítica II: 2006-2011. Primera parte”, Florentia Iliberritana, 22 (2011), pp. 217-266.

— , "Bibliografía analítica sobre la tradición clásica en las literaturas hispánicas e hispanoamericanas del siglo XX (II: 2006-2011). Segunda parte", Florentia Iliberritana, 23 (2012), pp. 163-207.

Cano Ballesta, Juan Luis, Nuevas voces y viejas escuelas en la poesía española (1970-2005), Atrio, Granada, 2007. 
Casanova, Pascale, La República mundial de las letras, traducción de Jaime Zulaika, Barcelona, Anagrama, 2001.

Castro, Adolfo de, (comp.), Poetas líricos de los siglos XVI y XVII, Vol. 1, Madrid, Atlas, 1950.

Catulo, Poesías, ed. bilingüe de José Carlos Fernández Corte y Juan Antonio González Iglesias, Madrid, Cátedra, 2006.

Comparetti, Domenico, Virgilio nel medio evo, Livorno, F. Vigo, 1872.

Cuenca, Luis Alberto, "La herencia grecolatina", Cuadernos Hispanoamericanos, 340 (1978), pp. 176-181.

Cristóbal López, Vicente, “Tradición clásica: concepto y bibliografía”, Edad de Oro, XXIX (2005), pp. 27-46.

—, "La tradición clásica en España. Miradas desde la Filología Clásica”, Minerva 26 (2013), pp. 17-51

Dávila, Arturo, Poemas para ser leídos en el metro, Huelva, Diputación Provincial, 2003.

Díaz de Castro, Francisco J., "La tradición clásica en la poesía española reciente: aproximaciones”, en Poesía española posmoderna, Madrid, Visor, 2010, pp. 63-99.

Díaz Rengifo, Juan, Arte poética española, Salamanca, Imprenta Miguel Serrano de Vargas, 1592.

Eliot, Thomas Stern, “Ulysses, Order, and Myth”, en Selected prose of T.S. Eliot, ed. de Frank Kermode, California, Harcourt Brace, 1975, pp. 175-178.

-, [1920], "La tradición y el talento individual", en La tradición y el talento individual, México, Universidad Nacional Autónoma de México, 2004, pp. 63-81.

Finley, Sir Moses, (ed.), [1981], The legacy of Greece. A new appraisal, Oxford, Oxford University Press, 1984.

García Gual, Carlos, "Cultura clásica y mundo actual”, en Año mil, año dos mil. Dos milenios de Historia de España (II), Madrid, Sociedad Estatal España Nuevo Milenio, 2001, pp. 253-266.

García Martín, José Luis, Selección nacional. Última poesía española, Gijón, Llibros del Pexe, 1995.

—, La generación del 99. Antología crítica de la joven poesía española, Oviedo, Nobel, 1999.

Gil de Biedma, Jaime, "Prólogo", a T.S. Eliot, Función de la poesía y función de la crítica, Barcelona, Tusquet, 1999, 9-29.

Gómez Espelosín, Francisco J., Los griegos, un legado universal, Madrid, Alianza, 2003.

Gruia, Ioana, Eliot y la escritura del tiempo en la poesía española contemporánea, Madrid, Visor, 2009.

Guerrero Contreras, Carmen, "El mito de Ariadna y Teseo en tres poetas españoles contemporáneos: Angel Pestime, Víctor Botas y David Pujante", Anuario de Estudios Filológicos, XXIV (2001), pp. 223-241.

Highet, Gilbert, [1949], La tradición clásica. Influencias griegas y romanas en la literatura occidental, 2 vols., México, FCE, 1996.

Immisch, Otto, Das Nachleben der Antike, Dieterich, Leipzig, 1919.

Jenkyns, Richard (ed.), The legacy of Rome. A new appraisal, Oxford, Oxford University Press, 1992.

Laguna Mariscal, Gabriel, La influencia de la poesía latina en la española durante el Renacimiento, en Actas de las II Jornadas de Humanidades Clásicas, 2001, pp. 40-50.

—, "La literatura Clásica como referencia para la Moderna: algunas reflexiones y pautas metodológicas", en Historia y mito. El pasado legendario como fuente de autoridad, Málaga, Servicio de publicaciones de la Diputación de Málaga, 2004a, pp.409-426. 
—, “De dónde procede la denominación Tradición Clásica?”, Cuadernos de Filología Clásica. Estudios Latinos, 24 (2004b), pp. 83-93.

Langbaum, Robert, [1957], La poesía de la experiencia. El monólogo dramático en la tradición literaria moderna, introducción y traducción de Julia Jiménez Heffernan, Granada, Comares, 1996.

Lázaro Carreter, Fernando, "Imitación compuesta y diseño retórico en la Oda a Juan de Grial”, Anuario de estudios Filológicos 2 (1979), pp. 89-119.

Lida de Malkiel, M. ${ }^{\text {a }}$ Rosa, La originalidad artística de la Celestina, Buenos Aires, Eudeba, 1962.

—, Estudios de Literatura Española y Comparada, Buenos Aires, Eudeba, 1966.

—, Dido en la literatura española. Su retrato y defensa, Londres, Tamesis Books, 1974.

— La tradición clásica en España, Barcelona, Ariel, 1975.

Livingstone, Sir Richard, (ed.), The Legacy of Greece: Essays, Oxford, Claredon Press, 1921. Luque, Aurora, Hiperiónida, Granada, Zumaya, 1982.

-, Camaradas de Ícaro, Madrid, Visor, 2003

—, "La siesta de Epicuro", Poética y poesía, 10 (2006), pp. 15-33.

—, Una extraña industria, Valladolid, Servicio de Publicaciones de la Universidad de Valladolid, 2008.

Manguel, Alberto, El legado de Homero, Barcelona, Debate, 2010.

Mengíbar, Inmaculada, Pantalones blancos de franela, Madrid, Hiperión, 1994.

Milán, Eduardo, Resistir. Insistencias sobre el presente poético, México, D.F., FCE, 2004.

Morán Rodríguez, Carmen, “Anúnciese en el aire: consumo y publicidad en la obra de Aurora Luque”, Pasavento 3.2, (2015), pp. 437-457.

Morano, Ciriaca, "El resurgir de lo mítico en la literatura contemporánea: diversos procedimientos de acceso al mito", Faventia, 4/1 (1982), pp. 77-93.

Morcillo, Françoise, La poesía española contemporánea leída como un diálogo entre culturas, Mallorca, La Lucerna, 2009.

Morros Mestres, Bienvenido, Las polémicas literarias en la España del siglo XVI: a propósito de Fernando de Herrera y Garcilaso de la Vega, Barcelona, QC, 1998

Newald, Richard, "Nachleben der Antike (1920-1929)", en Jahresbericht über die Fortschritte der klassischen Altertumswissenschaft, 232, Leipzig, Reisland, 1931, pp. 1-122.

Olmo Iturriarte, Almudena del y Díaz de Castro, Francisco J., (eds.), Versos Robados. Tradición clásica e intertextualidad en la lírica posmoderna peninsular, Sevilla, Renacimiento, 2011.

Paraíso, Isabel, "Fundación del canon métrico: el Arte Poética Española, de Juan Díaz Rengifo" en Retóricas y Poéticas españolas siglos XVI-XIX, Valladolid, Secretariado de publicaciones e intercambio editorial Universidad de Valladolid, 2000, pp. 47-93.

Peña, Juan, Días cansados, Valencia, Pre-Textos, 1997.

Riera, Carme, "El color de la blusa, por ejemplo", El Urogallo, 32 (1988), pp. 12-18.

Salvago, Javier, Ulises, Valencia, Pre-textos, 1996.

Sánchez de Brozas, Francisco, Francisci Sanctii Brocensis opera omnia. Opera poetica, vol. 4, Génova, Apud Fratres de Tournes, 1766.

Sánchez Dueñas, Blas, “Autobiografía y mitología: la vida a través del mito clásico en la poesía de Juana Castro”, en Poesía Histórica y (auto)biográfica (1975-1999), Madrid, Visor, 2000, pp. 555-569.

Saval, José Vicente, Carlos Barral, entre el esteticismo y la reivindicación, Madrid, Fundamentos, 2002.

Schlanger, Judith, La mémoire des œuvres, Nathan, 1992. 
Siles, Jaime, "Ultimísima poesía escrita en castellano: rasgos distintivos de un discurso en proceso y ensayo sobre una posible sistematización", Iberoromanía, 34 (1991), pp. 8-31.

Springer, Anton, "Das Nachleben der Antike im Mittelalter", en Bilder aus der neueren Kunstgeschichte, A. Marcus, Bonn, 1867.

Villena, Luis Antonio de, Teorías y poetas. Panorama de una generación completa en la última poesía española, Valencia, Pre-textos, 2000.

Vara Ferrero, Natalia, "Lecturas irónicas de la tradición clásica: el caso de Víctor Botas", en Versos Robados. Tradición clásica e intertextualidad en la lírica posmoderna peninsular, Sevilla, Renacimiento, 2011, pp. 207-227.

Viñas Piquer, David, Historia de la crítica literaria, Barcelona, Ariel, 2008.

VV. AA., L'eredità classica nel Medioevo. Il linguaggio comico, Viterbo, Agnosetti editore, Centro di studio sul teatro medioevale e rinascimentale, 1979.

Walsh, Peter G., "Epílogo", en Historia de la Literatura Clásica, Vol. II, Literatura Latina, Madrid, Gredos, 1989, pp. 849-855. 